\title{
Enhanced Performance of Induction Motor with Direct Field Oriented Control Drive using Space Vector Pulse Width Modulation
}

\author{
G.Nageswara Rao, K.R.L.Prasad, J.Sivavara Prasad
}

\begin{abstract}
This paper exhibits 3 level Neutral purpose Clamped electrical converter continuing choice motor with Direct Field organized management drive victimization house vector beat breadth amendment framework. the final examination of various degrees of surprised electrical converter for minimisation of torsion swell in AN acknowledgment motor. In AN enrollment motor reach extraordinary execution in the meantime transient condition, a prompt field organized management framework is completed. within the prompt field organized management strategy, decoupling of the torsion and alter conveyance of title parts of stator coil current, and perfection of dynamic execution within acknowledgment motor. The essential house vector beat breadth amendment system is related to truthful purpose cut inverter(NPC) in inference of location torsion. The planned procedure offer AN improved introduction in alteration of torsion swell strategy. the fast field masterminded management of two level svpwm arrange is differentiated and planned 3-level svpwm plot. torsion swell of the acknowledgment motor is compelled in victimization svpwm mostly direct field organized management methodology. The propagation results square measure shown to demonstrate relationship of $2 L$ and three level FOC management victimization svpwm framework.
\end{abstract}

Keywords- Space Vector Pulse Width Modulation, Field oriented control and Neutral point clamped inverter, Direct.

\section{INTRODUCTION}

Within recently the development of lofty control, fewer price and trustworthy power electronic converters ware an opportunity of victimization Brobdingnagian or medium acknowledgment motors in hemorrhage edge gift day drive applications. The Direct field organized management framework may be a remarkable management strategy for AN acknowledgment motors needs a free management of torsion and appealing movement as similar to in DC machine. choice motors varied world category has been exhibited. Field organized management of acknowledgment motor drive typically used as a results of its properties like high profitableness, ease, very intense, extraordinary power issue and doesn't need starter. the quality seductive movement dependent on Field headed management estimation for

Revised Version Manuscript Received on August 19, 2019.

G.Nageswara Rao, Professor, Electrical and Electronics Engineering Department, Lakireddy Bali Reddy College of Engineering, EEE Department, Mylavaram, Krishna Dt, A.P, India(e-mail: gnrgudipudi@gmail.com)

K.R.L.Prasad, Professor, Electrical and Electronics Engineering Department, Lakireddy Bali Reddy College of Engineering, EEE Department, Mylavaram, Krishna Dt, A.P, India(e-mail: gnrgudipudi@gmail.com)

J.Sivavara Prasad, Professor, Electrical and Electronics Engineering Department, Lakireddy Bali Reddy College of Engineering, EEE Department, Mylavaram, Krishna Dt, A.P, India (e-mail: gnrgudipudi@gmail.com) voltage mercantilism framework has relative ideal conditions of to realize decoupled management, essential structure and simple execution.

Space Vector beat breadth Modulation (SVPWM)technique endless offer of the mercantilism repeat. The mercantilism repeat management extents of 2-3 kilohertz ,the mercantilism repeat is sustained running beneath one kilohertz causes some defect in abatement of torsion swell and movement management. a pair of level electrical converter mercantilism occurrence is unbroken in issue and therefore the variable mercantilism repeat is not important in tall power make applications. The SVPWM system is employed to diminish the sounds, and mercantilism weight.

The days office surprised inverters square measure extensively employed in current applications. the rule electrical converter thought is employed to diodes and totally different voltage levels square measure given. the various periods of electrical device banks connected in course of action. The diode relations restricted proportion of voltage. It reduces the mercantilism anxiety of alternative electrical devices. The rule hassle of office electrical converter be yield voltage is $1 / 2$ the dc effort voltage. These issues are often appreciated by extending the diodes, signals and capacitors.

The acknowledgment motor exhibiting is implicit by victimization position packaging of speculation. A full consonant buckle(THD) of truthful purpose caught electrical converter is contemplate for power applications. The shut examination of two level and three level objective purpose caught electrical converter victimization SVPWM management framework.

In this paper analyzed the smart framework for minimisation of torsion swell, By seeing 2 level and 3 level nonracist purpose supported electrical converter strengthened enrollment motor drive victimization svpwm methodology. it's displayed for minimisation of torsion and alter management, full torsion at zero speed ,decrease Doctor of Theology

\section{NEUTRAL POINT CLAMPED INVERTER}

A chart of inverter is showed up in Fig. 1. It includes dc supply, 12 power components by a FD diode, 2 capacitors. It contains 3 legs and every leg contains 4 signals. The every leg trading state can be conveyed as in table1. Signals S2a and S1a are compliment to signals S4a and S3a 
independently. At the capacitor related in plan, there are assorted signals. The signals $\mathrm{S} 1 \mathrm{a}$ and $\mathrm{S} 2 \mathrm{a}$ is open on the stage is maintain . The signals $\mathrm{S} 2 \mathrm{a}$ and $\mathrm{S} 3 \mathrm{a}$ is open on the path is zero..

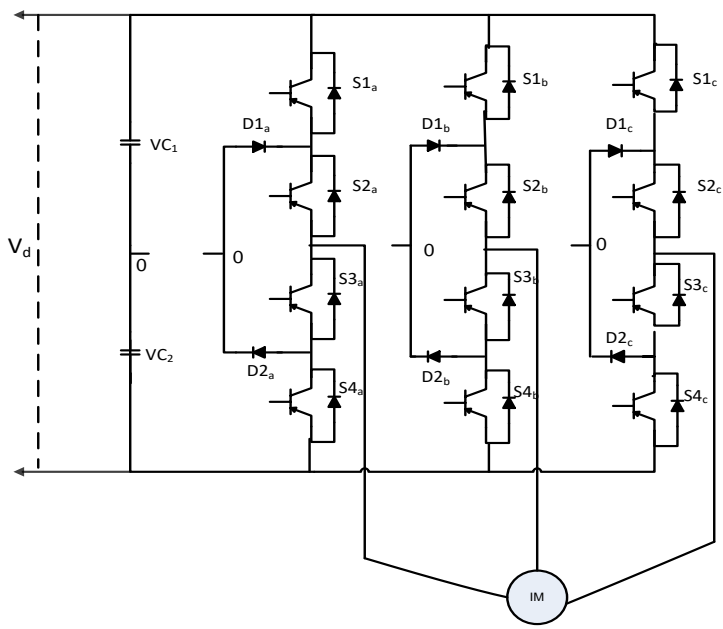

Fig1: Schematic of 3 phase 3 level NPC inverter TABLE. 1 Switching sequence

\begin{tabular}{|c|c|c|}
\hline $\begin{array}{c}\text { Signals } \\
\text { Turned ON }\end{array}$ & Pole voltage & Representation \\
\hline $\mathrm{S} 1 \mathrm{a}, \mathrm{S} 2 \mathrm{a}$ & $+v_{d} / 2$ & +1 \\
\hline $\mathrm{S} 2 \mathrm{a}, \mathrm{S} 3 \mathrm{a}$ & 0 & 0 \\
\hline $\mathrm{S} 3 \mathrm{a}, \mathrm{S} 4 \mathrm{a}$ & $-v_{d} / 2$ & -1 \\
\hline
\end{tabular}

In this neutral purpose cut (or)diode caught electrical converter procedure is employed as showed up in figure1. The mercantilism devices of the just purpose supported electrical converter should be listed, Then the right wave structure is turn out. the trail toward giving authentic portal pulses to the mercantilism devices is termed as modification technique for AN electrical converter. Here components S2a and S1a to be activate. The use of svpwm is creating V-J Day higher yield, In examination of spwm. The office electrical converter 3 various voltage levels, thus each leg will convey 3 clear.Table1:gives the various degrees of post voltages in house vector beat breadth amendment. each circumstance of a vector by one, $0,-$ one is termed as state of a vector.

\section{NEUTRAL POINT CLAMPED INVERTER}

The 3 level office electrical converter of the voltage vectors square measure showed up in figure2. The office electrical converter produces mercantilism states. In these states solely nineteen voltage vectors square measure dynamic voltage vectors have twofold abundance. These vectors square measure essentially disengaged into four social events; tremendous, little, medium and nil. The arduous and quick house vector plane isolated into half-dozen sections all of sixty degrees(between 2 tremendous vectors).In this house vector diagram three invalid vectors square measure bestowed. Beside zero vector they're 3 kinds of vectors, they're just about nothing, average, and big vectors. These spans and vectors square measure self-addressed in table. Fig2.voltage vectors of three level office

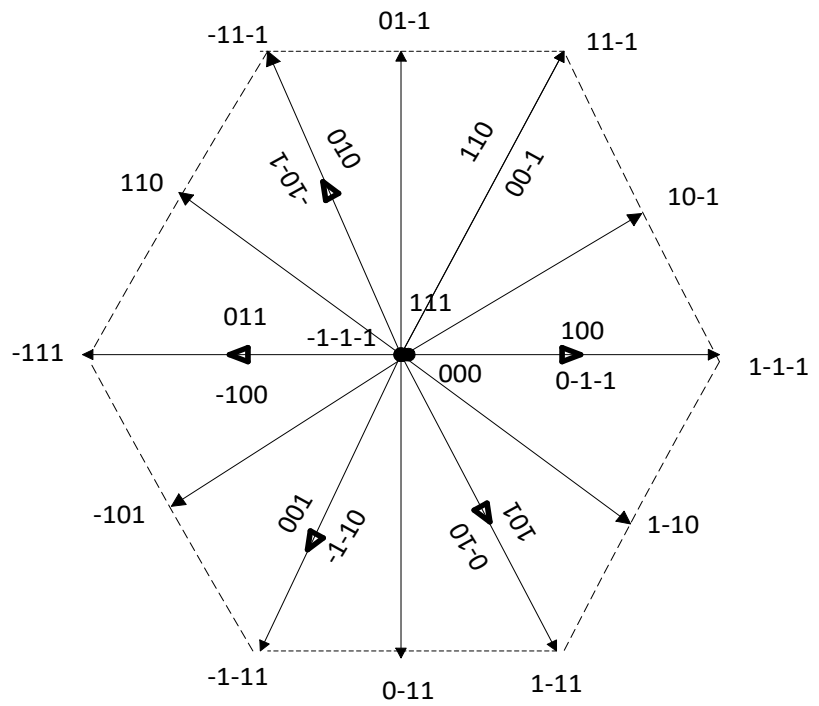

Fig2. 3 level NPC

Be Among the 3 svpwm additionally to a pair of path voltage signal, svpwm methodology the quantity of paths improve system is employed. The reference voltage house vector or take a look at.Then the Vref is in initial section by then notice the keep times of half one.in initial division notice the Vref is problematic. By then notice the centre of every vector.HereV3,V4,V5 square measure middle core interests. The region more doled out into very little triangle, center of mass of the every and each triangle and notice the division from indicator to center of mass that partition is not really Vref is displayed. at the moment Ts insinuated as inspecting time allotment. Differing voltage vectors that may be created by the electrical converter square measure associated over totally different time ranges with in an exceedingly observing timespan.

The 3 abundance vectors square measure (111),(000)and (one,- 1,- 1).In solicitation to acknowledge 3 part balance yield voltages. it'd be self-addressed should lean. Fig3. sector one in $\alpha \beta$ plane(vref) The house vectors are often comprehend the reference vector over $\mathrm{AN}$ assessing periods $\mathrm{V} 0, \mathrm{~V} 1, \mathrm{~V} 2, \mathrm{~V} 3, \mathrm{~V} 4, \mathrm{~V} 5$ and nil vector. we are able to choose any vector anyway initial selecting the closest reference vector. It offers higher arduous and quick consonant injury of yield voltage. For the closest vector square measure equality, the face up to time are often resolved.

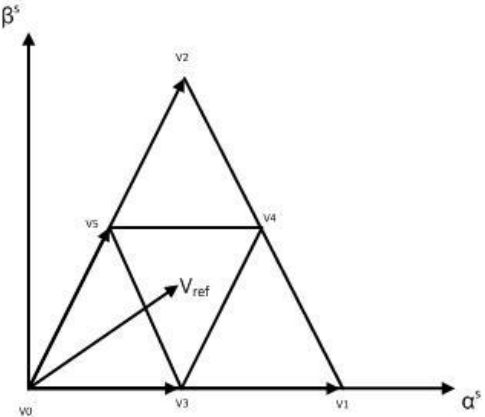

Fig3. sector 1 in $\alpha \beta$ plane(vref)

The space path canister be comprehend the mention over an assessing period $\mathrm{V} 0, \mathrm{~V} 1, \mathrm{~V} 2, \mathrm{~V} 3, \mathrm{~V} 4, \mathrm{~V} 5$ and zero vector. We anyway first picking the nearest reference vector. It gives 
better hard and fast consonant mutilation of yield voltage. V0,V1,V2from volt-sec equality, the withstand time can be resolved. Now T1,T2 are stay period.

$$
\begin{aligned}
{\left[\begin{array}{l}
V_{a} \\
V_{\beta}
\end{array}\right]=2 / 3\left[\begin{array}{ll}
1 & - \\
0 & \sqrt{?}
\end{array}\left[\begin{array}{l}
i a \\
i b \\
i c
\end{array}\right]\right.} \\
V_{r} T_{S}=V_{1} T_{1}+V_{2} T_{2}+V_{0} T_{0} \\
T_{1}=\frac{V_{r} T_{S}}{V_{1}} \cdot \frac{\sin \left(\theta_{2}-\theta_{r}\right)}{\sin \left(\theta_{2}-\theta_{1}\right)} \\
T_{2}=\frac{V_{r} T_{S}}{V_{2}} \cdot \frac{\sin \left(\theta_{1-} \theta_{r}\right)}{\sin \left(\theta_{1=} \theta_{2}\right)}
\end{aligned}
$$

\section{DIRECT FIELD ORIENTED CONTROL}

In field masterminded management ,the ground purpose is assessed by victimization lethal $\mathrm{v}$ and $\mathrm{i}$ or Flux intellect snaking. In the plan sq. style essentially, the squares getting used square measure PI controllers. The PI controller maily accustomed manage the development controller. The speed management separated and examination speed,the authentic speed secured either figurer block,the occurring into stator coil current The torsion controller is separated and real ,the subsequent into The reference for Theflux controller separated and real the subsequent into,by utilizing parks amendment dq square measure modified over into $\alpha \beta$. The figurer sq. is appeared ensuing into then separated and therefore the gift goofs on these lines got square measure old PI controllers that structure the current controller of the compel framework

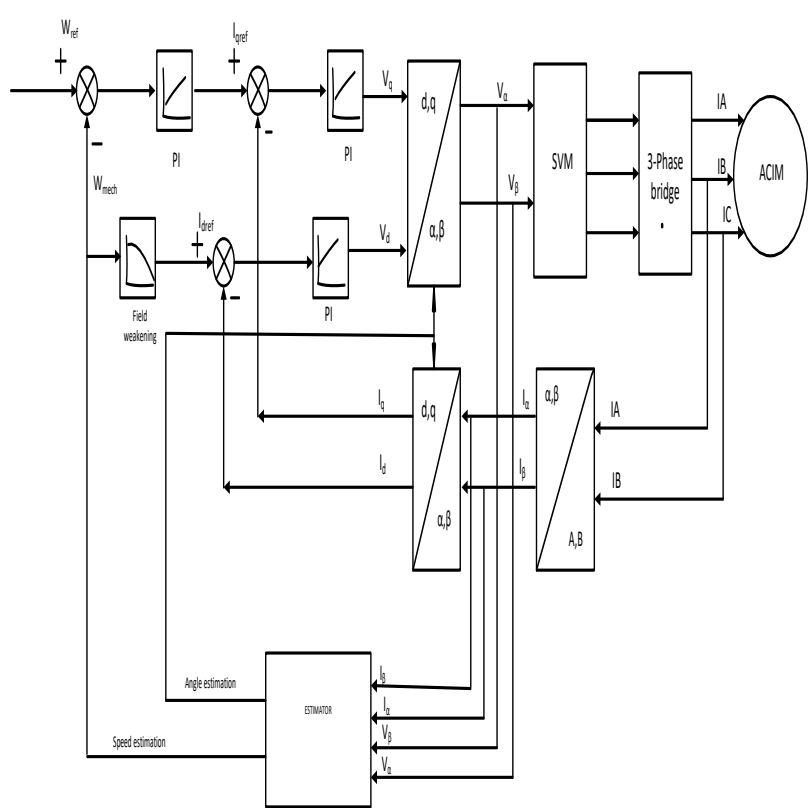

Fig3. Direct Field Oriented Control

\section{CONTROL STRATEGY}

Ordinary Management Procedures, The Volts-Hertz System. Management The Plentitude And Repeat Voltage. In Numerous Field Organized Management The Plentitude And Repeat And Time Of Motor Drive Voltage. The 3 Part Stator Coil Gift As That Management The Rotor Movement Vector And Rotor CurrentPhasor. By And By As Critical Maine On Top Of Perspective, Acknowledge That You Simply May Progress Within The Motor. After You Square Measure Within Running Adjacent The Flip Rotor At A Comparable Speed Because Amendment Vector Current Throughout Unshrinking State Streams Seem Like Predictable Characteristics, And Therefore The Turning Movement Vector Is Enduring. Management The Stator Coil Streams To Urge Required Rotor Streams. The Stator Coil Streams Are Often Managementled Like Dc Regards Victimization Normal Of The Rotor. To Alter From The Stator Coil Mounted Edge To The Rotor Rotating Layout, The Rotor Desires The Circumstance To Be Settled.

\section{SIMULATION RESULTS}

By utilizing Matlab/Simulink, the advantage of SVPWM function as a numerical reenactment has been finished mounted advancement size of. A 3-organize, 4 shaft, $37.3 \mathrm{kVA}, 1200 \mathrm{rpm}$ affirmation engine by parameters of Rs = zero. $183 \omega, \mathrm{Rr}=0.277 \omega, \mathrm{Ls}=0.0553 \mathrm{H}, \mathrm{Lr}=0.056 \mathrm{H}, \mathrm{Lm}=$ $0.0538 \mathrm{H}$ and $\mathrm{J}=0.06 \mathrm{Kg} . \mathrm{m} 2$ square measure thought-about., from which, it'll beat all be seen that the traditional FOC offers huge unbendable state swells and systematically symphonic bowing. To diminish the swells, SVPWM computation is employed for 2-level and three level office electrical converter. The duplication results for SVPWM calculation based mostly 2-level office electrical converter inspired FOC-IM drive and 3-level office electrical converter proceeded FOC - IM 
TABLE2: IM Specifications

\begin{tabular}{|l|l|}
\hline $\begin{array}{l}\text { power } \\
\text { line -line voltage(V1-1) }\end{array}$ & $\begin{array}{c}5 \mathrm{HP}, 746 \mathrm{~W} \\
400 \mathrm{~V}\end{array}$ \\
\hline $\mathrm{P}$ & 4 \\
\hline $\mathrm{J}$ & 0.06 \\
\hline frequency & $60 \mathrm{~Hz}$ \\
\hline $\mathrm{Rs}$ & $0.183 \Omega$ \\
\hline $\mathrm{Rr}$ & $0.277 \Omega$ \\
\hline $\mathrm{Ls}$ & $0.0553 \mathrm{H}$ \\
\hline $\mathrm{Lr}$ & $0.056 \mathrm{H}$ \\
\hline $\mathrm{Lm}$ & $0.0538 \mathrm{H}$ \\
\hline
\end{tabular}

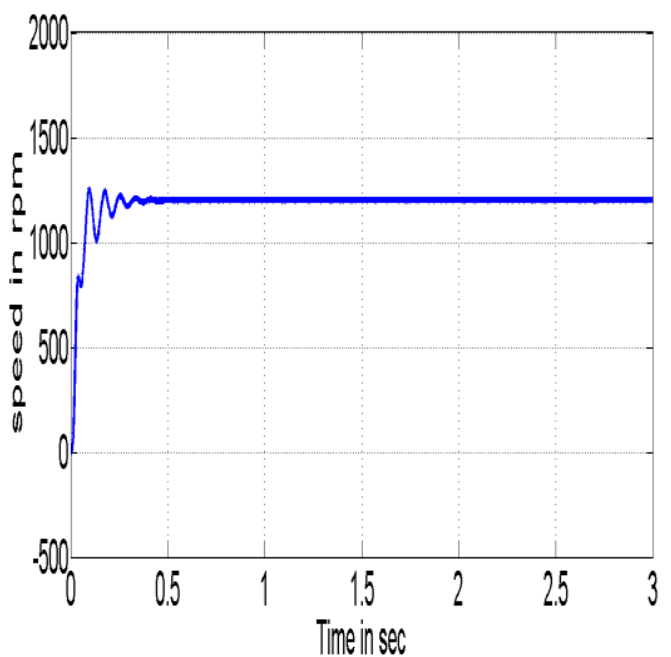

Fig(5):speed response of FOC 2-level

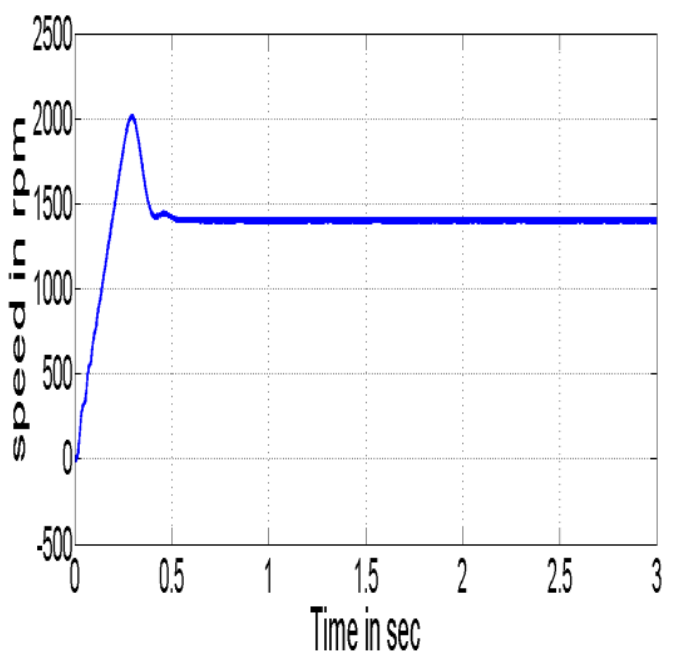

Fig (6):speed response of FOC 3 level under no load condition.

fig(5):gives the speed reaction of FOC two level below no heap form. Here the speed is $1200 \mathrm{rev}$ it achieves solid state at zero. $35 \mathrm{sec} . \mathrm{fig}(6)$ :gives the speed reply of FOC three level below no heap condition. Here the speed is $1400 \mathrm{rev}$,most imperative high over shoot happens at $0.2 \mathrm{sec}$ and it achieves enduring state at zero. $4 \mathrm{sec}$. we tend to chewed over each a pair of level electrical converter fig(5) and three level office electrical converter fig(6). By seeing that speed reaction higher mostly three level office electrical converter. thus this improvement improves appraisal being developed and business

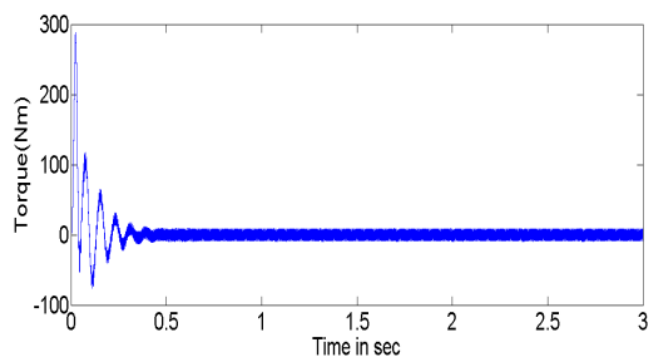

Fig(7):Torque response of FOC 2 level under No load condition

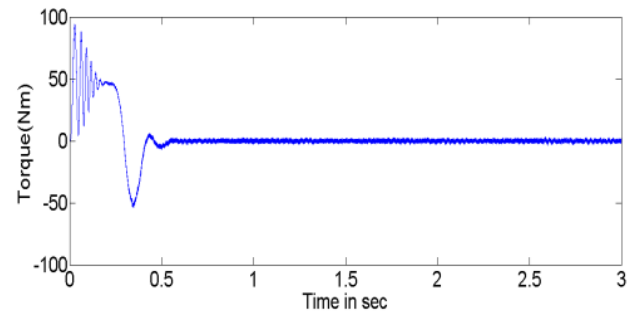

Fig(8):Torque response of FOC 3 level under No load condition

Fig(7):Torque response of FOC two level below Noloadcondition

Fig(8):Torque response of FOC three level below Noloadcondition

fig(7):gives the torsion response of FOC two level below no load condition. Here the torsion ripple is fig(8):gives the torsion response of three level FOC below no load condition. Here the torsion ripple is.

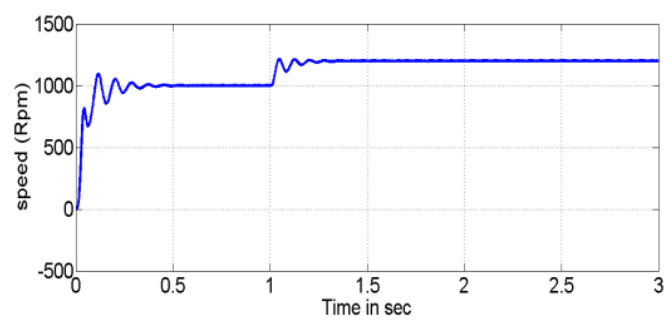

Fig(9):speed response of FOC 2 level under load condition.

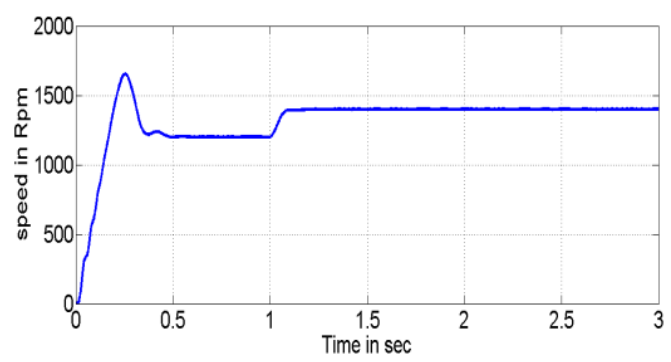

Fig(10):speed response of FOC 3 level FOC under load condition.

Fig(10):speed response of FOC three level below loadcondition.

fig(9):gives the speed reaction of FOC two level below weight condition. now the speed is a thousand rev it achieves enduring state at zero. $35 \mathrm{sec}$, and apply load at 1sec,the speed reaction is 1200rpm and achieves enduring at one. $3 \mathrm{sec}$. fig(10): gives the speed reaction of FOC three level below weight condition. Here the speed is $1200 \mathrm{rev}$,most ridiculous 
high over shoot happens at o.2sec and it achieves unbendable state at zero. $4 \mathrm{sec}$, and apply load at one sec the speed reaction is $1400 \mathrm{rev}$. we tend to looked fig(9) and fig(10), By seeing that speed reaction higher improvement in svpwm based mostly FOC three level below weight condition.

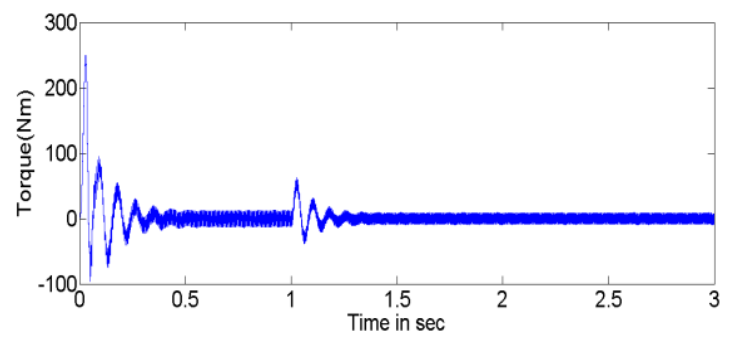

Fig(11):Torque response of 2 FOC level FOC under load condition.

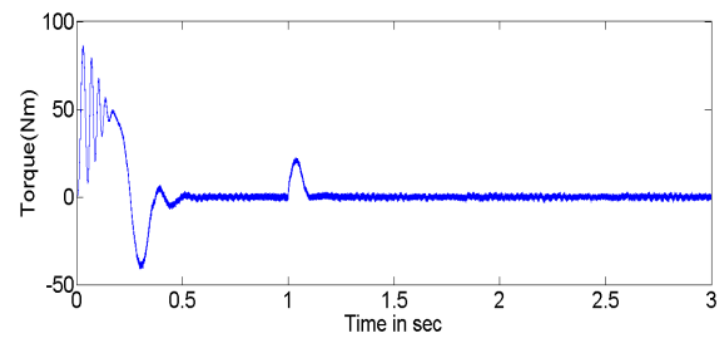

Fig(12): Torque response of FOC 3 level under load condition

Fig(12): torsion response of FOC three level below load condition

fig(11):gives the torsion reaction of FOC two level below weight condition. Here the torsion swell cannot avoid being swell is reduced.fig(8):gives the torsion reaction of FOC three level below weight clause ,after one sec we tend to apply load the torsion reaction is diminished $\mathrm{Nm}$. torsion swell is bated. we tend to looked fig(11) and fig(12),By seeing that the torsion reaction higher improvement in FOC three level lower weight condition.

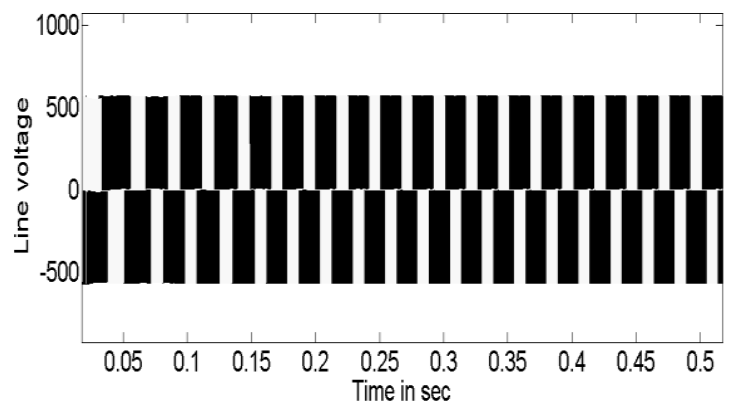

Fig(13):voltage response of FOC 2 level

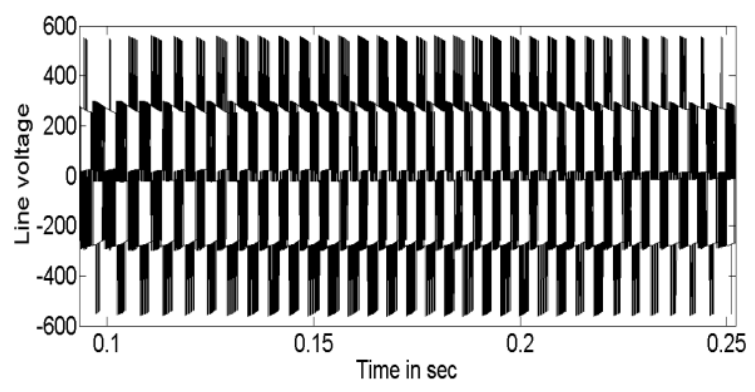

Fig(14):voltage response of FOC 3 level

fig(13):gives the voltage reaction of FOC 2 level and
Fig(13):voltage response of FOC two level

fig(14):gives the voltage reaction of FOC 3 level. we examined fig(13) and fig(14),By seeing that fig(14)the state of the wave structure is continuously sinusoidal, and the sounds is diminished in FOC 3 level inverter

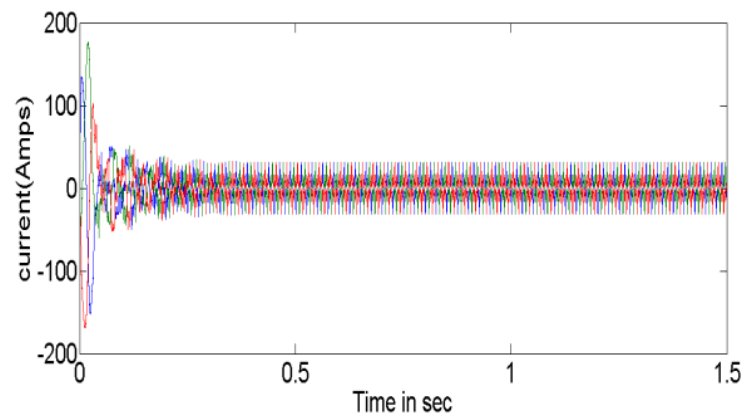

Fig(15):stator current response of 2 level FOC

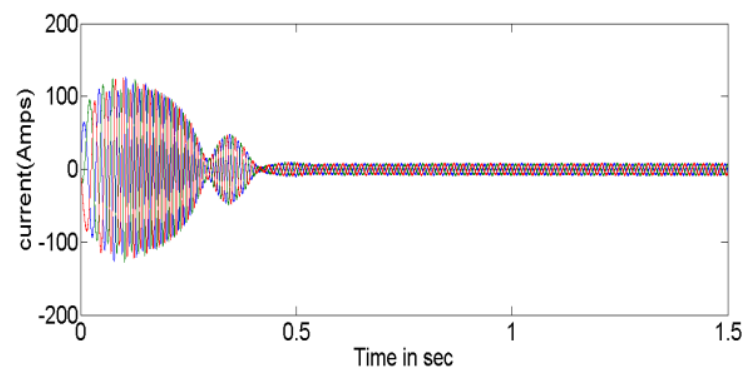

Fig(16):stator current response of FOC 3 level.

fig(15):gives the stator current reaction of FOC 2 level and fig(16): gives the present reaction of FOC 3 level. The fig(16),By view that the present swell is lessened in stator current reaction of FOC 3 level

\section{REFERENCES}

1. P. Rajasekaran1* and V. Jawahar Senthilkumar2 Comparative Analysis of Two Level VSI and Three Level Neutral Point lamped Inverter for Torque Ripple Reduction in Induction Drive. Indian Journal of Science and Technology, Vol 9(7), DOI: 10.17485/ijst/2016/v9i7/78751, February 2016

2. Amit Kumar, Tejavathu Ramesh DIRECT FIELD ORIENTED CONTROL OF INDUCTION MOTOR DRIVE 2015 Second International Conference on Advances in Computing and Communication Engineering

3. Indirect Field Oriented Control (IFOC) of Induction Motor Using SVPWM Fed with Zsource Inverter Ishtiyaque Ahmad and Dr. R.K Tripathi, Member, IEEE 978-1-4673-0455-9/12/\$31.00 @ 2012 IEEE

4. H. W. van der Broeck, H. C. Skudelny, and G. Stanke, "Analysis and realization of a pulse width modulator based on voltage spacevectors,"IEEE Trans. Ind. Applicat., vol. 24, pp. 142-150, Jan./Feb.1988

5. Y. Luo and W. Chen, "Sensorless stator field orientation controlled induction motor drive with a fuzzy speedcontroller," Computer and Mathematics with Appl., Vol.64, 2012, pp. 1206-1216

6. Peresada, A. Tonielli, and R. Morici, "High- Performance IndirectField-Oriented Output Feedback Control of Induction Motors," ElsevierScience, S. Peresada et al./ Automatica, vol. 35, pp. 1033-1047, 1999.

7. Busquets-Monge, J. Rocabert,P.Rodriguez, S. Alepuz, and 1. Bordonau,"Multilevel diode- clamped converter for Photovoltaic generators with independent Voltagecontrol 
of each solar array,"IEEE Trans. Ind.Electron. vol. 55, no.7, pp. 2713-2723, 2008

8. Gadoue S. M., Giaouris D., Finch J. W., 'MRAS sensorless vector control of an induction motor using new sliding-mode and fuzzy-logic adaptation mechanisms', IEEE Trans. Energy Conversion, 2010,Vol. 25, No. 2, pp. 394-402.

9. Yue F. and N. Elliott, " A simple modulation strategy to control the neutral point voltage deviation in three-level NPC inverters," Power Electronics, Machines and Drives (PEMD), pp. 1-5, April 2010. 